\title{
An Informatics Benchmarking Statement
}

\author{
K. Pigott' ', S. de Lusignan' ', A. Rapley², J. Robinson' ', A. Pritchard-Copley ${ }^{3}$ \\ 'Biomedical Informatics, Division of Community Health Sciences, St George's - University of London, \\ London, UK \\ 2Faculty of Computing, Information Systems and Mathematics, Kingston University, \\ Kingston-upon-Thames, UK \\ ${ }^{3}$ University of Wales College of Medicine, Cardiff University, Cardiff, Wales, UK
}

\begin{abstract}
Summary
Objectives: Benchmarking statements provide a mechanism for making academic standards explicit within a subject area. They allow comparisons between courses to be based on learning outcomes rather than by defining a curriculum. No such statement has been produced for informatics. In the absence of any established benchmarking statements for informatics a new biomedical informatics course at St. George's has developed a first benchmarking statement - which defines the skills knowledge and understanding a biomedical informatics student should acquire by the time they complete the course.

Methods: Review of national biomedical science and computing subject benchmarking statements and academic educational objectives and national occupational competencies in informatics.

Results: We have developed a twenty-item benchmarking statement and this is available on-line at: http://www.gpinformatics.org/benchmark2006/. This benchmarking statement includes a definition and justification for all twenty statements. We found international educational objectives and national informatics competencies useful and these are mapped to each one. National subject benchmarks for computing and biomedical science were less useful and have not been systematically mapped.

Conclusions: Benchmarking the skills, knowledge and understanding that a student should acquire during their course of study may be more useful than setting a standard curriculum. This benchmarking statement is a first step towards defining the learning outcomes and competencies a student of this discipline should acquire. The international informatics community should consider moving from a standard curriculum to an agreed subject benchmarking statement for medical, health and biomedical informatics.
\end{abstract}

\section{Keywords}

Benchmarking,informatics, curriculum, educational measurements, learning

Methods Inf Med 2007; 46: 394-398

doi:10.1160/ME0442

\section{Introduction}

Benchmarking is a method of measuring performance against established standards of best practice [1, 2]. Historically, benchmarks were made on survey stones as a reference point against which other topographical features might be measured. Benchmarking statements provide a useful mechanism for making academic standards explicit. Benchmarking statements were adopted first in North America in the 1990s, followed by Australia and the UK where they have been adopted by the UK-based Quality Assurance Agency (QAA) [3]. Benchmarking statements have also been implemented within the European Higher Educational Area (EHEA) as a tool to enable description of qualifications as well as an enabler of trans-national education (TNE) within Europe $[4,5]$. Within informatics benchmarking is also recognised so that informaticians are able to work globally [6, 7]; though as yet no such statement has been produced for informatics graduates.

Benchmarking statements should help ensure the quality of undergraduate informatics courses. Universities prepare students for the workplace through academic study and vocational courses; employers develop occupational standards to enable employees to understand the competencies that they need to have. Students achieve learning outcomes and acquire competencies as a result of their studies. These terms encompass the acquisition of knowledge and understanding, knowing how to act (this includes skills and practical activity) and knowing how to be (this includes social, legal and professional issues as well as living with others in a social context) [8].
The first full-time UK undergraduate biomedical informatics course has been developed at St George's, University of London, in collaboration with Kingston University and Royal Holloway, University of London $[9,10]$. This course can be completed as a bachelor's degree (BSc) after three years or as a master's (MSci) in science after four, with the option of adding an additional work placement between years two and three. The three-year BSc course consists of eight subject areas delivered through 24 modules; the eight subjects are taught with increasing complexity over the three years of the course following the principles of Bruner's spiral curriculum [11]. Four themes provide continuity of approach between the modules. The course was designed using the International Medical Informatics Association's (IMIA) guidance [12] and, in the absence of any informatics benchmarks, links in part to the computing and biomedical science benchmarks [3]. The course sets out to provide an academic grounding in biomedical informatics at the same time as being a vocational course for those looking to acquire skills and competencies for their future careers. Whilst the academic model came from IMIA, there are no internationally established core competencies for informaticians. We therefore adopted the NHS National Occupational Standards (NOS) for health informatics [13] and looked to ensure that students completing the course had the opportunity to achieve the first two levels of the NHS Information Management and Technology (IM\&T) professional awards [14].

In order to have a rational basis to link academic objectives and the need for vocational preparation for a career as a biomedical informatics professional we constructed a benchmarking statement for informatics. 


\section{Table 1 Definition of benchmarking standards}

A benchmarking standard is:
The conceptual framework that gives a discipline its coher-
ence and identity; about the intellectual capability and
understanding that should be developed, the techniques
and skills which are associated with developing an under-
standing in that discipline; and the level of intellectual de-
mand and challenge which is appropriate to that disci-
pline.

Table 2 St George's biomedical informatics course categories of learning outcomes (objectives), module subjects and themes

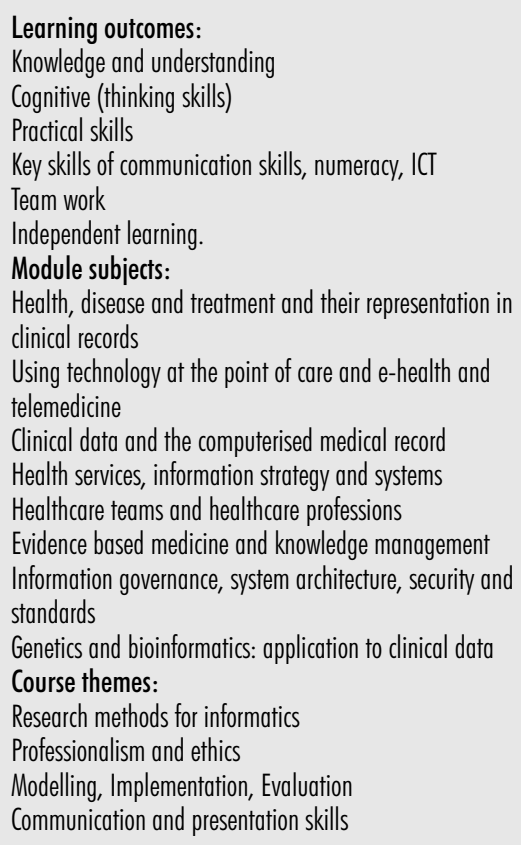

\section{Table 3 Benchmarking statements}

Level 1

1. Identify the need for IT applications in medicine and healthcare from the perspective of the patient and the healthcare professional and describe the importance of maintaining quality assured data processes.

2. Demonstrate competence in the use of appropriate technologies, communication and organisational skills to facilitate learning and development.

3. Apply organisational techniques to interpret information and use knowledge services; summarise information from multiple sources.

4. Deploy skills required in the administration of patients and their records and demonstrate awareness of the principles governing maintenance of manual and computing records.

5. Describe the characteristics of health and social care information systems.

6. Define basic terminology and theoretical concepts of informatics and computer science and list the strengths and weaknesses of e-communication in healthcare.

7. Explain concepts in mathematics and biometry with an emphasis on statistics and presentation of simple statistical reports.

Level 2

8. Discuss and apply advanced theoretical and practical applications of informatics and computer science.

9. Demonstrate use and design of software.

10. Present data and information processing skills, analyse and assess different coding systems in healthcare.

11. Define and evaluate informatics standards.

12. Display an awareness of the fields of Medicine, health and biosciences and NHS organisation.

13. Show appropriate and professional customer service skills.

14. Describe applications of biomedical informatics specialities.

Level 3

15. Critically discuss ethical issues, evaluate conflicts between technologically assisted patient care and patients' privacy.

16. Manage, implement and assess Information and Communication Technology, list issues governing effective ICT within healthcare.

17. Identify and synthesise solutions for technical/security faults and describe relative risks of different IT systems.

18. Present information regarding image and signal processing, list uses and theoretical underpinnings of these processes.

19. Plan, implement, monitor, evaluate and complete projects.

20. Exhibit managerial skills and knowledge, demonstrate financial awareness, apply problem-solving skills and describe different project management frameworks.

\section{Methods}

We conducted a literature review for informatics with searches on biomedical informatics courses and vocational qualifications using as search terms; medicine-, health-, biomedical-, bioinformatics-. Traditional bibliographic databases, e.g. Medline, Embase, were searched together with the web sites of the International Medical Informatics Association (IMIA); its Health and Medical Informatics Education Working Group (WG1) [15] and its affiliated organisations.
We first carefully reviewed the biomedical science and computing benchmarking statements produced by the UK Quality Assurance Agency (QAA) [3]. These statements provided useful elements used in the course, however, it immediately became clear that they could not be readily utilised to create a benchmarking statement for informatics.

We identified three internationally developed publications which define the academic scope of informatics: the recommendations of the International Medical Informatics Association (IMIA) on Education in Health and Medical Informatics [12] and the proceedings of a subsequent conference organised by its Education Working Group [16]. Secondly, education and training in health informatics (IT EDUCTRA) European standards work-sets index [17]. Thirdly, the British Computer Society's (BCS) Health Informatics Forum Education Steps (BCS-ES) [18]. We identified, also, nationally relevant and vocationally-orientated sources: National Occupational Standards for Health Informatics (NHS NOS), National Health Service vocational awards in Information Management and Technology (NHS IM+T) and the draft programme for the St George's, Kingston and Royal 
Table 4 Codes for British Computer Society Education Steps (BCS-ES) components

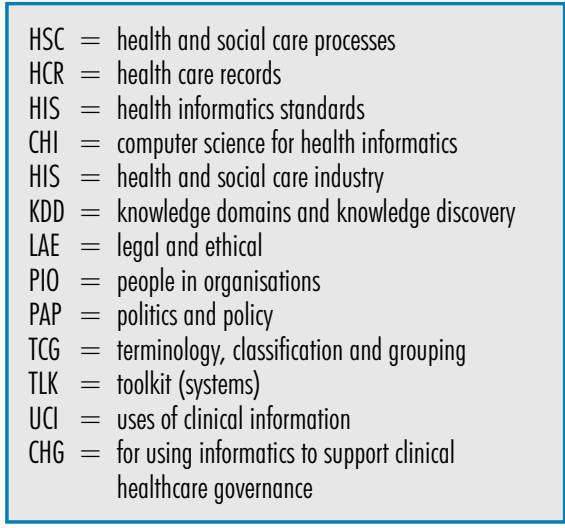

Holloway biomedical informatics course (GKH). We hand searched the IMIA Yearbooks 2002 to 2005 and the special editions of Methods of Information in Medicine which had education as a special topic.

The International Medical Informatics Association and NHS National Occupational Standards were mapped first to each other using codes to identify each component. Other sources were subsequently added to this basic tool and gradually 20 templates were built. We identified from these templates 20 common learning outcomes, which became benchmarking statements. We decided that learning objectives and vocational competencies can only appear once and decided only to map vocational competencies to one place in the learning hierarchy.

We developed definitions of the learning outcomes, justifications for the exclusivity of each learning outcome or benchmarking statement and classified each one under Bloom's (1956) taxonomy. A verb was allocated to each statement, giving evidence of one of the following: knowledge, comprehension, application of knowledge or understanding, analysis, synthesis, evaluation [19].

We organised the learning outcomes by level of learning, reflecting differences in operational context, cognitive or intellectual skills and key or transferable skills. Level of learning was defined in 1998 by the InterConsortium Credit Agreement Project (InCCA) as an indicator of the relative demand, complexity and depth of learning and of learner autonomy [20] and later by the QAA [21].

A web resource of the mapped learning objectives and vocational competencies was produced. This utilised a content management system that enabled the mapping of vocational competencies to academic objectives and the presentation of the mapping.

\section{Results}

The six sources identified by our literature search were mapped to produce 20 benchmark statements. Each of these benchmarking statements is linked to a form which included a more detailed definition of the statement, a justification, and the most relevant IMIA, EDUCTRA, BCS E-S, NHS NOS, and NHS IM+T objective or competency linked to it. The 20 benchmark statements are classified according to Bloom's (1956) taxonomy [19] and grouped by levels of learning [20,21]. The 20 statements are shown in Table 3 and can be viewed in more detail at: URL: http://www.gpinformatics. org/benchmark2006/

Within the on-line pilot benchmarking statement the IMIA recommendations are numbered according to their location in the three main sections of the source, i.e. Section 1 is "Methodology and technology for the processing of information and knowledge in medicine and health care". The first part of Section 1, "Reasons for the necessity of systematically processed data, information and knowledge in medicine and healthcare" was labelled 1.1a; the second $1.1 \mathrm{~b}$ and so on. We also developed a coding system for the British Computer Society Education Steps (BCS-ES) report (Table 4).

The components from EDUCTRA and NHS NOS are labelled as found in the original source material. The IT EDUCTRA is composed of units 1, 3, 4, 5 and 6 (there is no unit 2). Components in the NHS NOS are labelled through from HI1-HI119. The first component of Module A of the NHS IM+T is labelled $\mathrm{A} 1$, the first of the $\mathrm{B}$ module is labelled $\mathrm{B} 1$ and so on. The preceding letters $\mathrm{C}$ and D stand for Certificate and Diploma respectively. Other features of the tool table include cross-references to similar components.

The online database maps all the components of each source material once, to what we considered the most appropriate benchmarking statement.

\section{Discussion}

\subsection{Principal Findings}

There was considerable commonality between the existing international informatics academic objectives. It was also possible to map the UK national vocational competencies to an appropriate benchmarking statement. From a combination of academic objectives and vocational competencies we were able to produce benchmarking statements in the desired format, namely as learning outcomes.

\subsection{Implications of the Findings}

This first attempt to produce a benchmarking statement for biomedical informatics could be used in the UK to develop a definitive QAA-approved benchmark and internationally for the informatics community possibly as an IMIA activity. A benchmarking approach may offer advantages over the current approach of standardising curricula. Benchmarking learning outcomes and competencies achieved by students on their course may be of more value than listing the proportion of their timetable given over to a particular subject. What matters for the new informatics graduates and their employer is what knowledge they hold and what they can do, rather than whether their course had a standard curriculum.

The benchmarking statement will also be of use to higher education institutions currently offering or thinking of setting up such courses and to employers who would have a greater understanding of the learning outcomes students from such courses would have achieved. 


\subsection{Comparison with the Literature}

Relatively few new international informatics education standards have been published, despite the many recent changes in informatics. The IMIA standards are now over five years old [12], as is the EDUCTRA worksets index [17]. These initiatives pre-date the vast growth of bioinformatics (genetics and proteomics) recognised to be an important new dimension to informatics in Europe [22, 23] and North America [24]. Over this time period there has been widespread adoption of IT in healthcare [25]; a trend toward creating national IT systems [26] or systemic interoperability between distributed IT systems [27]. The BCS-ES initiative is more recent [18], but has also focussed on definition of a core curriculum rather than creating a benchmarking statement for biomedical informatics.

Benchmark statements are widely used in, around and beyond medicine and informatics. The UK Higher Education Academy is consulting on proposals for a new framework for professional standards for teaching and supporting students in learning in higher education [28]. In the medical profession benchmark data has been used, from cases of disease prevention e.g. evaluating disease outbreak detection methodology [29], through to treatment e.g. benchmarks for antibiotic use, quality improvement and cost in long-term nursing care [30].

\subsection{Limitations}

Whilst a subject benchmarking statement for informatics may offer the theoretical advantages that are described above there is no evidence that the curricula-based approach to informatics has failed. Curricula have been used as a mechanism to define and compare courses and how they have evolved with time [31-34]. Credits obtained during progression through the curriculum have formed the basis of credit transfer, allowing movement of students between courses [35]. Perhaps most importantly of all informatics graduates from well established courses find employment [36, 37].

A further limitation of this exercise was the decision to only map vocational com- petencies to one place in the learning hierarchy; we felt this made the benchmark easier to use - but inevitably was based on a judgement about best fit. Similarly there are potential weaknesses in our association of competencies with a single learning level.

We have not distinguished between medical, health and biomedical informatics; we believe there should be a single benchmarking statement across the health informatics disciplines. The authors' view is that there has been evolution from medical informatics, as the original discipline, to health informatics, to embrace the broader health agenda, to biomedical informatics. The move to biomedical informatics, as a title for the discipline, reflects the need to incorporate bio-informatics as a core part of the informatics discipline.

\subsection{Call for Further Research}

Further research is needed to validate this first benchmarking tool. Mapping existing curricula against the tool would indicate whether it had face validity. Consortia of interested parties should consider the further development of this tool and of internationally agreed core competencies for informatics professionals. Widespread adoption of a benchmark statement in informatics would make regulation of the profession much more straightforward and may be of interest to bodies such as the UK Council for Health Informatics Professions (UKCHIP).

\section{Conclusions}

Established academic learning outcomes and vocational competencies in informatics can be mapped together to produce a benchmarking statement for informatics. This benchmark statement provides a conceptual framework for biomedical informatics and the techniques and competencies that need to be acquired by a student of this discipline. The international informatics community should consider moving from a curricula-based standardisation of courses to one based on a subject benchmark for our discipline.

\section{Acknowledgements}

The research was carried out in the biomedical informatics group at St. George's. The contributions of all those involved with the development of this course (http://www.sgul.ac.uk/informatics) is acknowledged. APC worked on the first version of this benchmark as her final year elective.

\section{References}

1. Jackson N. Benchmarking in UK HE: An overview. Quality Assurance in Education 2001: 9 (4); 218-235.

2. University of Manchester. eLearning Resources Centre. Briefing: Benchmarking. URL; http:// www.elrc.ac.uk/download/publications/BriefingBenchmarkingv0.9.doc. Last access 5/3/07.

3. Quality Assurance Agency (QAA) for Higher Education. Benchmarking statements. URL: http://www.qaa.ac.uk/academicinfrastructure/ benchmark/honours/default.asp. Last access $5 / 3 / 07$.

4. The National Unions of Students within Europe (ESIB). European Student handbook on transnational education. URL: http://www.esib.org/ index.php?option $=$ com_docman\&task $=$ cat view\&gid=125\&Itemid=263. Last access 6/3/07.

5. Mantas J. Comparative educational systems. Stud Health Technol Inform 2004; 109: 8-17.

6. Hovenga EJ. Academic standards, credit transfers and associated issues. Stud Health Technol Inform 2004; 109: 18-27.

7. Hasman A, Haux R. Curricula in medical informatics. Stud Health Technol Inform 2004; 109: 63-74.

8. Towards benchmarking standards for taught masters degrees in computing. A report sponsored by the Council of Professors and Heads of Computing (CPHC) with the support of the UK Quality Assurance Agency (QAA). May, 2004.

9. St. George's - University of London. Biomedical Informatics Degree Course. URL: http://www. sgul.ac.uk/informatics. Last access 8/5/07.

10. de Lusignan S, Ellis B. Is the time right for direct entry into informatics? Informatics in Primary Care 2005: 13 (3): 167-170.

11. Bruner J. The Process of Education. Cambridge, MA: Harvard University Press; 1960.

12. International Medical Informatics Association (IMIA) Recommendations on Education in Health and Medical Informatics. Methods Inf Med 2000; 39: 267-277. URL: http://www.imia. org/wg1/rec.htm. Last access 5/3/07.

13. Skills for health. Health informatics - national occupational standards. URL: http://www. skillsforhealth.org.uk/view_framework.php?id= 48. Last access 5/3/07.

14. NHS Careers. Professional awards in information, management and technology (IM \& T) (Health). URL: http://www.connectingforhealth.nhs.uk/ delivery/serviceimplementation/modernisation/ etd/informatics/awards. Last access 6/3/07.

15. International medical informatics association (IMIA). Working Group 1: Health and Medical 
Informatics Education. URL: http://www.imia. org/wg1/. Last access 5/3/07.

16. Hovenga E, Mantas J. Global Health Informatics Education. Amsterdam: IOS Press; 2004.

17. Aarts J, Bloom S, Camman H. Education and training in health informatics (IT-EDUCTRA Worksets index (1999). URL: http://www. eihms.surrey.ac.uk/abbott/IT-EDUCTRA/html/ workindx.htm

18. British Computer Society, Health Informatics Forum. Radical education steps. URL: http:// www.differance-engine.net/educationsteps/ documents/otley2005outputs.htm. Last access $5 / 3 / 07$.

19. Bloom BS (ed). Taxonomy of Educational Objectives: The Classification of Educational Goals, New York, Toronto: Longmans; 1956.

20. Inter-Consortium Credit Agreement - InCCA. A common framework for learning: executive summary. URL: http://nicats.ac.uk/doc/INCCA.pdf. Last access 5/3/07.

21. Quality Assurance Agency (QAA) for Higher Education. The framework for higher education qualifications in England, Wales and Northern Ireland - January 2001. URL: http://www.qaa.ac. uk/academicinfrastructure/FHEQ/EWNI/default. asp\#specific. Last access 5/3/07.

22. Maojo V, Iakovidis I, Martin-Sanchez F, Crespo J, Kulikowski C. Medical informatics and bioinformatics: European efforts to facilitate synergy. Journal of Biomedical Informatics 2001; 34 (6): 423-427.

23. Martin-Sanchez F, Iakovidis I, Norager S, Maojo V, de Groen P, van der Lei J, Jones T, AbrahamFuchs K, Apweiler R, Babic A, Baud R et al. Synergy between medical informatics and bioinformatics: facilitating genomic medicine for future health care. Journal of Biomedical Informatics 2004; 37 (1): 30-42.
24. Friedman CP, Altman RB, Kohane IS, McCormick KA, Miller PL, Ozbolt JG, Shortliffe EH, Stormo GD, Szczepaniak MC, Tuck D, Williamson J; American College of Medical Informatics. Training the next generation of informaticians: the impact of "BISTI" and bioinformatics - a report from the American College of Medical Informatics. J Am Med Inform Assoc 2004; 11 (3): 167-172.

25. Mantas J, Hasman A, editors. Health and medical informatics education. Methods Inf Med 2007; 46: 50-92.

26. National Health Service. NHS Connecting Health: The National Programme for Information technology. URL: http://www.connectingfor health.nhs.uk/. Last access 5/3/07.

27. National Library of Medicine. Commission on Systemic Interoperability. URL: http://www.nlm. nih.gov/archive//20060215/csi/csi_home.html. Last access 5/3/07.

28. Higher Education Academy. A standards framework for teaching and supporting student learning in higher education. URL: http:// www.heacademy.ac.uk/documents/Standards_ Framework.pdf. Last access 5/3/07.

29. Kulldorff M, Zhang Z. Benchmark data and power calculations for evaluating disease outbreak detection methods. MMWR Morb Mortal Wkly Rep 2004; 53 Suppl: 144-151

30. Mylotte JM, Keagle J. Benchmarks for antibiotic use and cost in long-term care. J Am Geriatr Soc 2005; 53 (7): 1117-1122.

31. Kushniruk A, Lau F, Borycki E, Protti D. The school of information science at the university of Victoria, towards an integrative model for health informatics education and research. In: Haux R, Kulikowski C, editors. IMIA Yearbook of Medical Informatics 2006. Methods Inf Med 2006; 45 (Suppl 1): 159-165.
32. Zvárová J. Biomedical Informatics Research and Education at the EuroMISE Center. In: Haux R, Kulilowski C, editors. IMIA Yearbook of Medical Informatics 2006. Methods Inf Med 2006; 45 (Suppl 1): 166-173.

33. Leven FJ, Knaup P, Schmidt D, Wetter T. Medical informatics at Heidelberg/Heilbronn: status evaluation - new challenges in a specialised curriculum for medical informatics after thirty years of evolution. Int J Med Inform 2004; 73 (2): 117-125.

34. Jaspers MW, Fockens P, Ravesloot JH, Limburg M, Abu-Hanna A. Fifteen years medical information sciences: the Amsterdam curriculum. Int $\mathrm{J}$ Med Inform 2004; 73 (6): 465-477.

35. Hovenga EJ. Academic standards, credit transfers and associated issues. Stud Health Technol Inform 2004; 109: 18-27

36. Patton GA, Gardner RM. Medical informatics education: the University of Utah experience. J Am Med Inform Assoc 1999; 6 (6): 457-465.

37. Knaup P, Frey W, Haux R, Leven FJ. Medical informatics specialists: what are their job profiles? Results of a study on the first 1024 medical informatics graduates of the Universities of Heidelberg and Heilbronn. Methods Inf Med 2003; 42 (5): 578-587.

Correspondence to:
Simon de Lusignan
Course Director
Biomedical Informatics
Division of Community Health Sciences
St George's - University of London
London SW17 ORE
UK
E-mail: slusigna@sgul.ac.uk

